\title{
RADIOGRAFÍA DE UNA PROPUESTA OLVIDADA: LA PROPOSICIÓN DE REFORMA CONSTITUCIONAL DE LA JUNTA GENERAL ASTURIANA SOBRE DEMOCRACIA SEMIDIRECTA
}

\author{
Overview of a forgotten proposal: The proposal \\ for constitutional reform by the General Council of Asturias \\ on semi-direct democracy
}

\author{
Daniel López Rubio \\ Profesor de Derecho Constitucional \\ Universidad Carlos III de Madrid \\ dlr.eq1@gmail.com / daniel.lopez@uc3m.es
}

http://dx.doi.org/10.18543/ed-67(2)-2019pp263-295

Recibido: 19.07.2019

Aceptado: 16.12.2019

\section{Resumen}

El Anteproyecto de Constitución elaborado en 1978 por la ponencia de la Comisión Constitucional contempló un amplio catálogo de mecanismos de democracia semidirecta. Tras el intento del partido radical italiano, en junio de ese mismo año, de derogar vía referéndum el sistema de financiación pública de los partidos políticos, el temor a que un empleo populista de los mismos pudiera impedir la consolidación de la arquitectura constitucional llevó al constituyente a diluir intensamente la propuesta primigenia, resultando un modelo de democracia basado, casi incontestablemente, en la representación. Casi cuarenta años después, la Junta General del Principado de Asturias lanza en 2014 una proposición de reforma constitucional a las Cortes Generales, sugiriendo recuperar parcialmente algunas de las ideas previstas en aquel Anteproyecto. El artículo pretende analizar en detalle los elementos de esta interesante propuesta, destacando sus virtudes y defectos a la luz de la experiencia comparada. 


\section{Palabras clave}

Referéndum; iniciativa legislativa popular; democracia semidirecta; reforma constitucional.

\section{Abstract}

The draft of the Constitution made in 1978 by the Constitutional Commission comprised a broad set of mechanisms of semi-direct democracy. In June the same year, after the attempt by the Italian Radical Party to derogate the system for the public financing of political parties through a referendum, a fear that populists would use those mechanisms to prevent the consolidation of the constitutional regime led the constituent to considerably soften the original proposal, resulting in a model of democracy based, almost undoubtedly, in representation. Almost forty years later, in 2014, the General Council of the Principality of Asturias put forward to the Spanish Parliament a proposal to reform the Constitution, which suggested the partial recovery of some of the ideas of that draft. This paper aims to analyse in detail the key elements of this interesting proposal, by highlighting its virtues and flaws considering comparative experiences.

\section{Keywords}

Referendum; popular legislative initiative; semi-direct democracy; constitutional reform. 


\begin{abstract}
SUMARIO: I. INTRODUCCIÓN. LA DEMOCRACIA DIRECTA EN LA CONSTITUCIÓN DE 1978. II. EL ORIGEN DE LA PROPUESTA. III. LOS CAMBIOS PROPUESTOS (I): REFORMA DEL ARTíCULO 87.3. IV. LOS CAMBIOS PROPUESTOS (II): REFORMA DEL ARTÍCULO 92. 1. Cambios en el referéndum consultivo. 2. Incorporación del referéndum abrogativo. V. Los CAMBIOS PROPUESTOS (III): REFORMA DEL ARTÍCULO 166. VI. REFLEXIONES FINALES. BIBLIOGRAFIA.
\end{abstract}

\title{
I. INTRODUCCIÓN. LA DEMOCRACIA DIRECTA EN LA CONSTITUCIÓN DE 1978
}

El 24 de mayo de 2014 la Junta General del Principado de Asturias aprobaba una proposición de reforma constitucional -la primera emprendida por una Comunidad Autónoma- centrada en los artículos 87.3, 92 y 166 de la Constitución. Desde entonces la propuesta, que fue admitida a trámite por la Mesa del Congreso de los Diputados el 21 de octubre de 2014, duerme el sueño de los justos en la Cámara Baja. La inestabilidad política que arrancó en España el año 2015, y que ha traído tres elecciones generales en un lustro, ha enterrado en el olvido una muy interesante proposición, a cuyas principales virtudes y defectos dedicaremos este estudio.

La proposición, tomando conciencia de la escasa influencia de los mecanismos de democracia semidirecta en nuestro actual sistema constitucional, pretende dar un nuevo impulso a los mismos, introduciendo cuatro novedades fundamentales:

i) La posibilidad de que la iniciativa legislativa popular afecte a materias propias de ley orgánica.

ii) La ampliación de los sujetos legitimados para activar un referéndum consultivo.

iii) La creación de una modalidad abrogativa de referéndum.

iv) La incorporación de la iniciativa popular en el ámbito de la reforma constitucional.

Como es de sobra conocido, el artículo 23 de la Constitución consagra como derecho fundamental la participación política de los ciudadanos en los asuntos públicos, y lo hace abarcando sus dos vertientes fundamentales: la representativa y la directa. Así, el artículo reconoce «el derecho de participar en los asuntos públicos, directamente o por medio de representantes, libremente elegidos en elecciones periódicas por sufragio universal». El desarrollo de este precepto, en lo relativo a la participación directa, fue muy restrictivo en el articulado constitucional. Referéndum e iniciativa legislativa popular, las dos únicas instituciones que, junto con el concejo abierto, el 
Tribunal Constitucional considera desarrollo del derecho fundamental de participación política ${ }^{1}$, son configurados por el texto supremo de un modo extraordinariamente limitado.

En primer lugar, el artículo 87.3 de la Constitución sujeta el empleo de la iniciativa legislativa popular a la obtención de no menos de 500.000 firmas -compárese, por ejemplo, con las 50.000 exigidas en Italia ${ }^{2}$ - e impide el mismo en materias propias de ley orgánica, tributarias o de carácter internacional, así como en lo relativo a la prerrogativa de gracia. En segundo lugar, el referéndum queda limitado a cuatro únicos supuestos: i) el consultivo del artículo $92 \mathrm{CE}$, cuya iniciativa corresponde en exclusiva al Presidente del Gobierno; ii) los de acceso a la autonomía y reforma estatutaria (artículos 151 y $152 \mathrm{CE}$ ); iii) los de reforma constitucional, vía artículos $167 \mathrm{CE}$ (facultativo a iniciativa de una décima parte de las Cámaras) y $168 \mathrm{CE}$ (preceptivo); y iv) los que puedan realizarse, siempre previa autorización del Estado por imperativo del artículo 149.1.32 CE, en los diversos niveles territoriales, y que en la actualidad solo encuentran materialización en el ámbito local (artículo 71 de la Ley de Bases del Régimen Local).

Esta regulación acredita, como expresa Garrorena (1991: 148), «una filosofía o concepción de la democracia que está -para decirlo apretadamente- más cerca de Montesquieu que de Rousseau, más próxima a la confianza en los representantes (...) que al ejercicio de la capacidad de participar». En efecto, la Constitución de 1978 situó al Parlamento como el eje central de toda la vida pública, renunciando incluso a complementar su acción con mecanismos de participación directa ágiles. El Tribunal Constitucional (STC 103/2008, FJ 2) ha insistido en ello, subrayando que el referéndum es

«un cauce especial o extraordinario, por oposición al ordinario o común de la representación política, pues no en vano el art. 1.3 CE «proclama la Monarquía parlamentaria como forma de gobierno o forma política del Estado español y, acorde con esta premisa, diseña un sistema de participación política de los ciudadanos en el que priman los mecanismos de democracia representativa sobre los de participación directa», siendo así que «el propio Texto constitucional, al regular las características de los instrumentos de participación directa, restringe su alcance y condiciones de ejercicio», de suerte que, en el caso de otra manifestación típica de la democracia directa, como es la iniciativa legislativa popular, su ejercicio «sobre determinadas materias, por lo delicado de su naturaleza o por las implicaciones que entrañan, queda reservado a la mediación de los representantes políticos» (STC 76/1994, de 14 de marzo, FJ 3)».

\footnotetext{
1 STC 119/1995, FJ 3.

2 Artículo 71 de la Constitución italiana de 1948.
} 
Resulta vital recordar, sin embargo, que esta apuesta tan decidida por arrinconar los mecanismos de participación directa no fue una constante de todo el proceso constituyente. Antes al contrario, el Anteproyecto de Constitución redactado por los siete ponentes nombrados en el seno de la Comisión de Asuntos Constitucionales y Libertades Públicas apostaba por otorgar a estos instrumentos un peso mucho mayor. Así, el artículo 80 de aquel Anteproyecto establecía para la iniciativa legislativa popular: i) la limitación estricta del número de firmas exigidas a quinientas mil; ii) la posibilidad de emplear el mecanismo en materia de ley orgánica; y iii) en conexión con el artículo 157, la posibilidad de emplear la iniciativa popular en el ámbito de la reforma constitucional.

En relación con el referéndum, el artículo 85 del Anteproyecto contemplaba: i) un referéndum sobre leyes aprobadas y aún no sancionadas, a propuesta del Gobierno, a iniciativa de cualquiera de las Cámaras, o de tres Asambleas de territorios autónomos; ii) un referéndum sobre decisiones políticas de gran trascendencia, con idéntica iniciativa; y iii) un referéndum derogatorio sobre leyes en vigor, que añadía la iniciativa de setecientos cincuenta mil electores. Por su parte, en el ámbito de la reforma constitucional, el artículo 158 establecía la necesidad de referéndum en cualquier reforma constitucional.

El inicial entusiasmo que despertaban los instrumentos de participación ciudadana directa fue tornándose en total escepticismo, con un recorte espectacular tanto en el elenco como en su configuración. Así, en primer lugar, sería aprobada en el ámbito de la Comisión una enmienda in voce de Óscar Alzaga que acortaba el terreno de juego de la iniciativa legislativa popular, pues fijaba las quinientas mil firmas como un umbral mínimo ampliable por la ley orgánica que quedaba llamada a regular «las formas de ejercicio y los requisitos» de la institución.

El siguiente hito del proceso de recorte vino dado por la Comisión en lo relativo a las figuras referendarias contempladas en el artículo 85 del Anteproyecto. La ya célebre enmienda in voce presentada por Jordi Solé Tura supuso lo que Illueca (2018: 31) califica de «demolición completa de la arquitectura constitucional del referendo que proponía este precepto». En efecto, la enmienda suprimía las dos modalidades legislativas de referéndum, perviviendo únicamente el relativo a decisiones políticas de gran trascendencia, cuyos efectos pasaban a ser consultivos y cuya iniciativa quedaba reservada al Presidente del Gobierno - previa aprobación del Congreso. La enmienda obtuvo el respaldo mayoritario de los grupos parlamentarios, aunque encontró un rechazo frontal en la figura de Manuel Fraga Iribarne.

En el momento de presentar su enmienda, el diputado Solé Tura puso el foco en los riesgos que podrían derivarse para el naciente sistema democrático del empleo de los instrumentos de participación directa. Así, en relación 
con los referendos legislativos, expresó su temor hacia «la posibilidad de que la soberanía del Parlamento [fuera] absolutamente menoscabada», pudiendo producirse «conflictos muy serios entre Gobierno, Rey y Parlamento» ${ }^{3}$. En su turno en contra, Fraga Iribarne negaba que debiera preservarse la soberanía del Parlamento, recordando que la Constitución no habla de tal cosa sino «de la soberanía nacional que reside en el pueblo español, del que emanan todos los poderes del Estado, incluyendo, naturalmente, al Parlamento ${ }^{4}$. En este sentido, el diputado de Alianza Popular manifestó su deseo de que el artículo 85 perviviera tal y como fue redactado por la ponencia, evitando así cualquier intento de reinstalar la soberanía del Parlamento «a través del predominio único y exclusivo de los partidos políticos» $»^{5}$.

Solé Tura respondió a estos argumentos incidiendo en la necesidad de garantizar «que el órgano legislativo máximo, que son las Cortes, funcione con claridad y que no haya mecanismos de interferencia que puedan menoscabar esa labor ${ }^{6}$. Además, quiso referirse de modo específico a las preocupaciones de Fraga Iribarne sobre la probabilidad de que el recorte propuesto en el artículo 85 del Anteproyecto terminara por provocar una peligrosa partitocracia:

«Yo creo que el tema de la partitocracia se presta a muchísimas deformaciones; pero en un país donde precisamente no ha sido éste el mal fundamental, sino precisamente la negación de la existencia de los partidos, creo que en este momento contemplar o denunciar el mal de la partitocracia es un mal servicio a la causa de la consolidación de la democracia que intentamos llevar adelante. Aquí el problema que tenemos hoy no es la partitocracia, sino conseguir que los partidos funcionen, conseguir que los partidos sean representativos, que los partidos tengan fuerza, que los partidos sean reconocidos como intérpretes concretos de las grandes masas de la población y eso es lo fundamental» ${ }^{7}$.

Sumándose a la posición del diputado comunista, Gregorio Peces-Barba empleó su turno para destacar algunos problemas recurrentes de los referendos, como la posibilidad de manipulación en la pregunta, la polarización del debate político y social en torno a dos grandes bloques y la simplificación de los temas ${ }^{8}$. Sobre esta base, reiteró su apoyo a la enmienda «por un deseo de consolidación de la democracia en nuestro país $\rangle^{9}$.

${ }^{3}$ Diario de Sesiones del Congreso de los Diputados - Comisión de Asuntos Constitucionales y Libertades Públicas, núm. 81, 6 de junio de 1978, p. 2937.

4 Ibid. p. 2939.

${ }^{5}$ Ibid.

6 Ibid., p. 2942.

7 Ibid.

8 Ibid. p. 2943.

9 Ibid. p. 2944. 
Tras el debate, la enmienda fue sometida a votación, logrando ser aprobada por treinta y tres votos a favor, solo dos en contra y sin abstenciones. De este modo, la redacción original del artículo 85, que tanto espacio dejaba a la práctica referendaria, quedaba absolutamente demolida. Sobre las razones que estarían detrás de este giro de ciento ochenta grados se ha escrito mucho. En ocasiones se apunta a la experiencia plebiscitaria franquista, así como a la práctica gaullista en torno al artículo 11 de la Constitución francesa de 1958, como elementos que debieron pesar en los componentes de la Comisión ${ }^{10}$. Ello nos resulta, sin embargo, poco convincente. Téngase en cuenta que los principales defensores del giro emprendido -como Solé Tura, Peces-Barba, Pérez-Llorca o Miquel Roca- habían formado parte de la ponencia que tan entusiastamente dotó de pleno contenido al artículo 85 del Anteproyecto. Pues bien, en el momento de su redacción ambas prácticas eran perfectamente conocidas, resultando poco probable que solo vinieran a la mente de estos diputados en el debate de Comisión. Resulta más plausible que algún episodio acaecido entre uno y otro momento hiciera saltar las alarmas contra el referéndum y provocara la puesta en marcha del proceso de recorte. La respuesta, en efecto, se encontraba en Italia. El 11 de junio, es decir, apenas cinco días después de aquel debate en la Comisión, se celebrarían en la República italiana dos importantes referendos.

El 1977 el Partido Radical italiano puso en marcha una potente campaña de recogida de firmas para llevar a las urnas la derogación de ocho leyes de temáticas muy distintas. Su objetivo era, como ha dicho Luciani (2008: 14), «hacer más difícil el diálogo entre DC y PCI; abrir dentro de la mayoría y de la oposición fuertes contradicciones, crearse un espacio político más amplio (...), trasladando el terreno de la confrontación de la sede parlamentaria a las plazas y a las urnas referendarias». En suma, el Partido Radical quiso emplear el mecanismo referendario como vehículo para presentar al electorado un auténtico programa político alternativo. A resultas del proceso de control de admisibilidad sustanciado sobre las propuestas, la Corte Constitucional emitió una sentencia, ya célebre, en la que se vio obligada a enunciar límites al referéndum abrogativo más allá de los expresamente dispuestos por el artículo 75 de la Constitución. En base a estos nuevos límites, cuatro de las ocho consultas propuestas fueron declaradas inadmisibles. El parlamento evitó la convocatoria de otros dos referendos procediendo a modificar la

${ }_{10}$ Véase, por ejemplo, Oliver Araujo (1989: 141-142). En contra de la consideración de la práctica franquista como elemento motivador del proceso de recorte, encontramos a Vírgala Foruria (2013: 19), que entiende que «ni su utilización fue lo que mantuvo al régimen franquista en el poder ni tampoco fue un mecanismo utilizado de forma continuada (hay que recordar que Franco solo convocó dos referenda: 1947 Ley de Sucesión; 1966 LOE)». 
normativa que pretendía derogarse. De los dos referendos que quedaban en pie, uno de ellos resultaba totalmente disruptivo, pues planteaba la abolición de la financiación pública de los partidos. Muy probablemente deba verse esta consulta como el principal motor del proceso de recorte impulsado por Solé Tura y respaldado por la mayoría de los grupos de la Comisión ${ }^{11}$. De hecho, como sostiene Illueca (2018: 32), el hecho de que los resultados del referéndum fueran sumamente ajustados, con un 43,6\% del electorado italiano apostando por el sí a la derogación de la ley de financiación de partidos, hacía ya especialmente difícil que en momentos posteriores del debate constituyente pudiera recuperarse, total o parcialmente, la redacción original del artículo 85 del Anteproyecto.

El proceso de recorte siguió pocos días después, el 20 de junio, con la interposición por parte del diputado Cisneros Laborda -otro de los siete ponentes responsables del artículo 85 original- de dos nuevas enmiendas in voce, esta vez encaminadas a la supresión de la iniciativa popular en el ámbito de la reforma constitucional y de la necesidad de celebrar obligatoriamente referéndum para ratificar cualquier modificación del texto supremo ${ }^{12}$. Las enmiendas fueron aprobadas sin problemas, con la solitaria oposición del grupo de Alianza Popular.

El golpe definitivo al esquema de participación directa diseñado por el texto acontecería en el ámbito de la Comisión Mixta Congreso-Senado. Pese a no ser un punto que despertara conflicto alguno entre las Cámaras -cuya resolución suponía el cometido principal de la Comisión- se procedió a restringir aún más la iniciativa legislativa popular, incorporándose entre las materias vedadas a la misma aquellas propias de ley orgánica.

El texto final, pues, excluía el empleo del referéndum del proceso legislativo -pese a lo cual el artículo 92 siguió incardinado en el Capítulo II del Título III, denominado «De la elaboración de las leyes»-, suprimía toda iniciativa popular de referéndum, mantenía un referéndum de ámbito estatal meramente consultivo, y restringía extraordinariamente la iniciativa legislativa popular, que no solo no podría emplearse en materias propias de ley orgánica sino que tampoco podría operar en el ámbito de la reforma constitucional. La voluntad de asentar y dar estabilidad al naciente sistema democrático de partidos parece la razón fundamental de tan drástico recorte, siendo evidente que el episodio italiano debió constituir un recordatorio crucial del

${ }^{11}$ El diputado Peces-Barba llegó a referirse, si bien con suma parquedad, al reciente episodio italiano como ejemplo de que el referéndum podía dar lugar a «prácticas antidemocráticas». Véase Diario de Sesiones del Congreso de los Diputados - Comisión de Asuntos Constitucionales y Libertades Públicas, núm. 81, 6 de junio de 1978, p. 2943.

12 Véase Diario de Sesiones del Congreso de los Diputados - Comisión de Asuntos Constitucionales y Libertades Públicas, núm. 93, 20 de junio de 1978, pp. 3462-3466. 
riesgo que podían ofrecer los instrumentos de participación directa de cara a la consecución del objetivo.

La visión pausada de estos antecedentes resulta imprescindible a los fines de nuestro trabajo por dos motivos. Primero, porque, tal y como reconoce explícitamente el Preámbulo de la proposición de reforma constitucional elevada a las Cortes por la Junta General asturiana, la propuesta trata de recuperar buena parte de las fórmulas de democracia semidirecta plasmadas originalmente en el Anteproyecto. Segundo, porque en la reflexión sobre la pertinencia de aprobar la propuesta deberán tenerse en cuenta los motivos que llevaron al constituyente a su exclusión, debiendo plantearse si, cuarenta años después, perviven o no.

\section{ORIGEN DE LA PROPUESTA}

Entre junio y diciembre de 2011 miles de personas respaldaron con su firma la propuesta «Por la democracia directa» ${ }^{13}$, que pedía recuperar buena parte de los instrumentos participativos suprimidos durante los debates constituyentes. Empleando el derecho de petición reconocido en el artículo 29 de la Constitución, los ciudadanos solicitaron a sus respectivos Parlamentos autonómicos que hicieran uso, para alcanzar esta meta, de su facultad de elevar proposiciones de reforma constitucional a las Cortes Generales. En Asturias fueron siete mil setecientas las personas que se dirigieron a la Junta General del Principado para solicitar la articulación de una reforma constitucional que reconociera el derecho de los ciudadanos a pedir la convocatoria de un referéndum, a decidir sobre la abrogación de un texto legal en vigor o a solicitar una reforma constitucional.

Un año después, el grupo de Izquierda Unida en la Junta General de Asturias hacía suya la propuesta ciudadana y decidía impulsar su tramitación parlamentaria, empleando para ello el cauce de proposición de reforma constitucional. La propuesta original registrada en el Parlamento autonómico $^{14}$ recogía: i) la supresión de todos los límites materiales a la iniciativa legislativa popular; ii) la incorporación del referéndum sobre leyes aprobadas y no sancionadas y también del de derogación de leyes en vigor; iii) la previsión de la iniciativa popular para activar ambos referendos, así como el relativo a decisiones políticas de gran trascendencia; iv) la conversión en vinculante de este último referéndum; y v) la admisión de la iniciativa popular en el ámbito de la reforma constitucional.

13 Todo lo relativo a este movimiento ciudadano puede consultarse en: https://porlademocraciadirecta.org/entradas1/ (consultado el 10 de julio de 2019)

${ }_{14}$ Puede consultarse en el Boletín Oficial de la Junta General del Principado de Asturias, Serie A, núm. 16.1, de 12 de diciembre de 2012. 
El debate sobre la toma en consideración fue sustanciado en la sesión plenaria del 24 de mayo de $2013^{15}$, recibiendo la propuesta el apoyo de los grupos parlamentarios de Izquierda Unida, Socialista y Mixto. Votaron en contra los grupos popular y de Foro Asturias. El representante de Izquierda Unida, González Alvarez, apeló en su turno de intervención a la «creciente desafección y desconfianza hacia la política», impulsada en buena medida por la crisis económica. En su opinión, las fuerzas políticas tenían la obligación de «romper con este presente y de abrir una nueva etapa democrática que dote de los instrumentos y las prácticas necesarias para permitir la recuperación de esa confianza perdida» ${ }^{16}$. Así, la propuesta «pretende trasladar a la ciudadanía la sensación de que hemos entendido el mensaje, nos hemos puesto manos a la obra para ir cambiando la arquitectura institucional del país, empezando por darles la voz directa que hasta ahora se les ha vedado en buena medida» ${ }^{17}$.

Coincidió en el diagnóstico y en la solución el diputado Prendes Prendes, que intervino como representante de UPyD en el Grupo Mixto. Destacó, pues, la necesidad de emprender un proceso de regeneración democrática en España, que «devuelva la política a los ciudadanos» y que «restaure la confianza en el buen funcionamiento de las instituciones públicas». Para ello, añadió, iniciativa legislativa popular y referéndum «constituyen dos herramientas fundamentales ${ }^{18}$. Por su parte, el diputado socialista Lastra Valdés subrayó la paradoja de que la propuesta fuera defendida por Izquierda Unida, habiendo sido el profesor Solé Tura, comunista, el principal impulsor del recorte en el modelo. Asimismo, recordó al partido popular que fue su antiguo Presidente de honor, Fraga Iribarne, el mayor defensor del artículo 85 original $^{19}$. Coincidiendo en la necesidad de mejorar los complementos a la democracia representativa, emitió su parecer favorable a la toma en consideración del texto.

El diputado popular Rodríguez Feito recurrió a los riesgos de «abrir el melón de la reforma constitucional», y consideró la propuesta un «intento de alarmar y agitar a la sociedad española y asturiana con cuestiones que únicamente interesan a unos pocos $\rangle^{20}$. Criticó, igualmente, su origen, destacando que fue «el resultado de la petición llevada a cabo en Asturias por el 0,77\% de la ciudadanía, es decir, siete mil setecientas personas, una minoría

${ }^{15}$ Diario de Sesiones de la Junta General del Principado de Asturias, Serie P, núm. 60, de 24 de mayo de 2013.
16 Ibid., p. 5.
17 Ibid., p. 6.
18 Ibid., p. 9.
19 Ibid., p. 15.
${ }^{20}$ Ibid., p. 11. 
mayoritariamente vinculada al movimiento $15-\mathrm{M}$, o simpatizantes con él, un movimiento promovido desde grupos de extrema izquierda o antisistema ${ }^{21}$. En cuanto al contenido de la propuesta, el diputado entendió que a través de estos mecanismos Izquierda Unida pretendía «limitar la acción del Gobierno democráticamente elegido por todos los españoles», considerando además que la Constitución ya recoge «un amplio abanico de oportunidades para participar en su desarrollo»» ${ }^{22}$.

Finalmente, en opinión de la diputada de Foro Asturias Coto de la Mata, la propuesta «es un exceso, que supera además lo que existe en cualquier país». Su aprobación supondría, pues, «transformar nuestro sistema político, claramente representativo, en un sistema de representación directa, pero con unos requisitos y un alcance que harán que sea casi asambleario» ${ }^{23}$. Pese a todo, la diputada manifestó su simpatía por el aumento del alcance de la iniciativa legislativa popular.

Sobre la propuesta de modificar el artículo 92, fueron presentadas enmiendas por los grupos socialista, mixto y de Foro Asturias ${ }^{24}$. Este último defendió, directamente, la supresión de la nueva redacción propuesta al artículo, justificando su posición en que la «pretensión de instaurar, con carácter obligatorio, la celebración de un referéndum para la aprobación de una ley, para su derogación o sobre cualquier cuestión política con la mera solicitud de quinientos mil electores supone (...) implantar un sistema de representación directa, pero con unos requisitos de tipo asambleario». La ponencia nombrada en el seno de la Comisión de Presidencia desestimó la enmienda.

Las enmiendas de los grupos socialista y mixto iban encaminadas a suprimir el carácter vinculante del referéndum sobre decisiones políticas de gran trascendencia, eliminar el referéndum sobre leyes aprobadas y aún no sancionadas, y rodear de cautelas el derogatorio. Así, éste solo podría convocarse a iniciativa de quinientos mil ciudadanos, y no podría emplearse en determinadas materias -tributarias, presupuestarias, internacionales o relativas a la prerrogativa de gracia en la propuesta socialista, y solo presupuestarias e internacionales en la del grupo mixto. La ponencia de la Comisión decidió redactar un texto transaccional entre ambas propuestas, que finalmente sería plasmado en su informe ${ }^{25}$. En él quedaron recogidos los tres objetivos de las enmiendas originales, siendo las materias finalmente excluidas del

\footnotetext{
21 Ibid.

22 Ibid.

${ }^{23}$ Ibid., p. 13.
}

${ }^{24}$ Pueden consultarse en el Boletín Oficial de la Junta General del Principado de Asturias, Serie A, núm. 16.9, de 26 de marzo de 2014.

${ }_{25}$ Véase el Boletín Oficial de la Junta General del Principado de Asturias, serie A, núm. 16.11, de 3 de julio de 2014. 
referéndum derogatorio las presupuestarias, tributarias e internacionales, así como las relativas a la prerrogativa de gracia.

En cuanto al artículo 87.3, el grupo socialista planteó una enmienda con el fin de impedir el empleo de la iniciativa legislativa popular en materias tributarias o de carácter internacional, en lo relativo a la prerrogativa de gracia, y cuando implique incremento de los gastos o disminución de los ingresos de los Presupuestos Generales del Estado. En su enmienda en relación con este artículo, el grupo mixto apostaba por los mismos límites materiales que el grupo socialista, con la salvedad de las cuestiones tributarias y la prerrogativa de gracia. Además, eliminaba la consideración de las quinientas mil firmas como un mínimo que la Ley Orgánica reguladora de la figura pudiera incrementar. Finalmente, el grupo de Foro Asturias, pese a haber mostrado su disposición a la reforma del artículo 87.3, presentaba ahora una enmienda de supresión de la propuesta en relación con este artículo, por considerar la ausencia de límites materiales una posición extrema. De las tres enmiendas surgió un texto transaccional que supuso la retirada de todas ellas, y que fue aprobado por todos los grupos salvo el popular. Se mantuvieron en él las quinientas mil firmas como número máximo para poder emplear la iniciativa, y quedaron fijados como límites materiales la Ley de Presupuestos Generales del Estado, las materias tributarias e internacionales, y lo relativo a la prerrogativa de gracia $^{26}$.

El informe de la ponencia, respaldado por la Comisión en su Dictamen del 11 de julio de 2014, resultaría aprobado por el Pleno de la Junta General el 19 de septiembre del mismo año. Ofreciendo argumentos muy similares a los planteados en la toma en consideración, votaron a favor del texto los grupos de Izquierda Unida, socialista y mixto, y se opusieron los grupos popular y de Foro Asturias. Así pues, por 23 votos a favor y 22 en contra, la proposición quedó aprobada y pudo ser traslada a la Mesa del Congreso de los Diputados.

El 21 de octubre de 2014 la Cámara baja admitió a trámite la proposición de reforma constitucional ${ }^{27}$. Prácticamente justo un año después, el 26 de octubre de 2015, el Presidente del Gobierno disolvía las Cortes Generales y convocaba elecciones generales, sin que la propuesta hubiera llegado a someterse a su toma en consideración. Como es sabido, las proposiciones de origen autonómico no caducan tras la disolución de las Cámaras ${ }^{28}$, por lo que

26 Ibid.

${ }^{27}$ Boletín Oficial de las Cortes Generales, serie B, núm. 194-1, de 24 de octubre de 2014, pp. 1-3.

${ }_{28}$ El artículo 207 del Reglamento del Congreso de los Diputados establece que «disuelto el Congreso de los Diputados o expirado su mandato, quedarán caducados todos los asuntos pendientes de examen y resolución por la Cámara». Pese a lo contundente de la 
el texto fue trasladado a la siguiente legislatura ${ }^{29}$. El nuevo mandato de las Cámaras fue breve, pues el fracaso continuado en el proceso de elección de nuevo Presidente del Gobierno activó la disolución automática de las Cortes (artículo 99.5 de la Constitución). De este modo, la propuesta se trasladó de nuevo a la legislatura emanada de las elecciones generales de junio de $2016^{30}$. Durante el tiempo de la misma, el trámite de toma en consideración nunca llegó a llevarse a cabo, siendo tan notable demora difícil de justificar. Las elecciones generales de marzo de 2019 abrieron un nuevo mandato de las Cámaras, permaneciendo la proposición asturiana a la espera del arranque de su tramitación parlamentaria ${ }^{31}$.

Casi cinco años después de su aprobación por la Junta General del Principado de Asturias, la proposición de reforma constitucional permanece olvidada en el Congreso de los Diputados. Compartimos con Garrido López (2019: 341-343) la identificación de dos motivos centrales detrás de esta preterición: en primer lugar, la existencia en los últimos años de una serie de referendos cuyos resultados han sido impactantes -la aprobación de la salida del Reino Unido de la Unión Europea; la derrota de la propuesta de reforma constitucional Renzi-Boschi en Italia; el rechazo griego al plan de rescate elaborado por la Troika; el fracaso del plan de paz suscrito entre el gobierno colombiano y las FARC...; en segundo lugar, el hecho de que cualquier debate sobre la institución referendaria tiende a vincularse en España con los intentos secesionistas catalanes. En estas circunstancias, la propuesta se mantiene en hibernación a la espera de su consideración parlamentaria. Los siguientes epígrafes serán dedicados a su estudio sustantivo, ofreciendo las principales ventajas e inconvenientes de todos y cada uno de los elementos objeto de la misma.

redacción, existen dos excepciones a la regla general de caducidad de las iniciativas pendientes. Así, en primer lugar, la Ley Orgánica 3/1984, reguladora de la iniciativa legislativa popular, fija en su artículo 14 la no caducidad de las proposiciones provenientes del ejercicio de este instrumento. En segundo lugar, y en lo que a nosotros interesa, las sucesivas Mesas del Congreso vienen considerando que las iniciativas provenientes de las Comunidades Autónomas no caducan con la disolución de las Cortes Generales. GarcíaEscudero Márquez (2006: 223 y ss.) subraya, sin embargo, que esta excepción se aplica siempre y cuando el Congreso no haya procedido a la toma en consideración de la proposición autonómica. De haberlo hecho, explica la autora, ya no estaríamos ante una propuesta proveniente de un sujeto ajeno a la Cámara, «sino que habría sido asumida por ella en ejercicio de su facultad de iniciativa legislativa.

${ }_{29}$ Boletín Oficial de las Cortes Generales, serie D, núm. 758, de 20 de noviembre de 2015 , p. 1473.

${ }^{30}$ Boletín Oficial de las Cortes Generales, serie D, núm. 76, de 20 de mayo de 2016, p. 477.

31 Boletín Oficial de las Cortes Generales, serie D, núm. 519, de 27 de marzo de 2019, p. 1193. 


\section{LOS CAMBIOS PROPUESTOS (I): LA REFORMA DEL ARTÍCULO 87.3 CE}

La modificación propuesta de la regulación constitucional de la iniciativa legislativa popular gira en torno a dos grandes elementos. Primero, el levantamiento de buena parte de sus restricciones materiales; segundo, la limitación del número de firmas máximo exigible. Con ambas medidas, especialmente con la primera, la proposición trata de revitalizar una herramienta cuya regulación actual la hace escasamente atractiva a la ciudadanía. Entre 1983 y 2018 se han presentado 140 iniciativas, de las cuales 45 fueron inadmitidas en términos absolutos, 45 caducaron y 10 fueron rechazadas en la toma en consideración. Del resto tan solo dos han logrado ser aprobadas -una directamente, aunque con modificaciones respecto de la propuesta original, y otra a través de su subsunción en otra iniciativa-, aunque este dato debe ser relativizado: los ciudadanos disponen de capacidad de iniciativa, pero la responsabilidad última en el procedimiento legislativo es de las Cortes Generales. Así pues, lo relevante no es que las propuestas lleguen o no a ser respaldadas por las Cámaras, sino que logren ser discutidas. El hecho de que solo una porción relativamente baja de las proposiciones puestas encima de la mesa por los ciudadanos haya llegado a ser debatida en el Parlamento sí es un hecho ilustrativo de la escasa funcionalidad actual del instrumento ${ }^{32}$.

La proposición asturiana trata en primer lugar, como se ha dicho, de hacer más atractiva la iniciativa legislativa popular eliminando relevantes restricciones materiales. En efecto, el texto aprobado por la Junta General del Principado excluye de entre las materias vedadas aquellas propias de ley orgánica. La presencia de este límite, ausente en el Anteproyecto de Constitución elaborado por la ponencia, impide la actividad propositiva ciudadana en gran cantidad de asuntos: el desarrollo de los derechos fundamentales y las libertades públicas; los Estatutos de Autonomía; el régimen electoral general; la estabilidad presupuestaria; el Tribunal Constitucional; el Defensor del Pueblo; el Consejo General del Poder Judicial... La magnitud de la exclusión resulta desproporcionada ${ }^{33}$, máxime si tenemos en cuenta, como lo

32 Díaz-Revorio (2018: 256), subraya que las cifras también acreditan la necesidad de que los parlamentarios muestren una «mayor sensibilidad hacia este tipo de propuestas que los propios representantes habían ‘olvidado' o de cualquier forma no habían considerado».

${ }_{33}$ Pese a ello, el Tribunal Constitucional consideró en su sentencia 76/1994 que ninguna infracción constitucional se cometía por el hecho de que el propio texto supremo «al regular las características de los instrumentos de participación directa, restrinja su alcance y condiciones de ejercicio y, más concretamente, que la iniciativa legislativa sobre determinadas materias, por lo delicado de su naturaleza o por las implicaciones que entrañan, quede reservado a la mediación de los representantes políticos». 
hace García Majado (2017: 1046), que el principio democrático «no sólo exige que el Legislador dialogue con la ciudadanía, sino que dicho diálogo se intensifique cuando están en juego materias cuyo calado y repercusión social son especialmente profundos».

Resulta injustificado que, en aspectos de gran interés para la ciudadanía, como la regulación de sus derechos fundamentales o del régimen electoral general, a ésta le esté vetado el planteamiento de proposiciones. Recuérdese que la iniciativa legislativa popular en nada compromete la soberanía legislativa de las Cámaras, que son libres no solo de aprobar o no el texto, sino incluso de no tramitarlo denegando su toma en consideración. En estas circunstancias, limitar el hecho de que los ciudadanos eleven sus propias propuestas en materias de tanta relevancia para ellos carece de todo sentido. De hecho, parece probable que buena parte del fracaso de esta herramienta en cuatro décadas de vigencia constitucional responda a estas restricciones materiales ${ }^{34}$, habida cuenta de que 45 de las 140 proposiciones intentadas (prácticamente un tercio) no lograron despertar interés entre los electores, fracasando en la recolección del número exigido de firmas (véase gráfico $1^{35}$ ).

\section{Gráfíco 1}

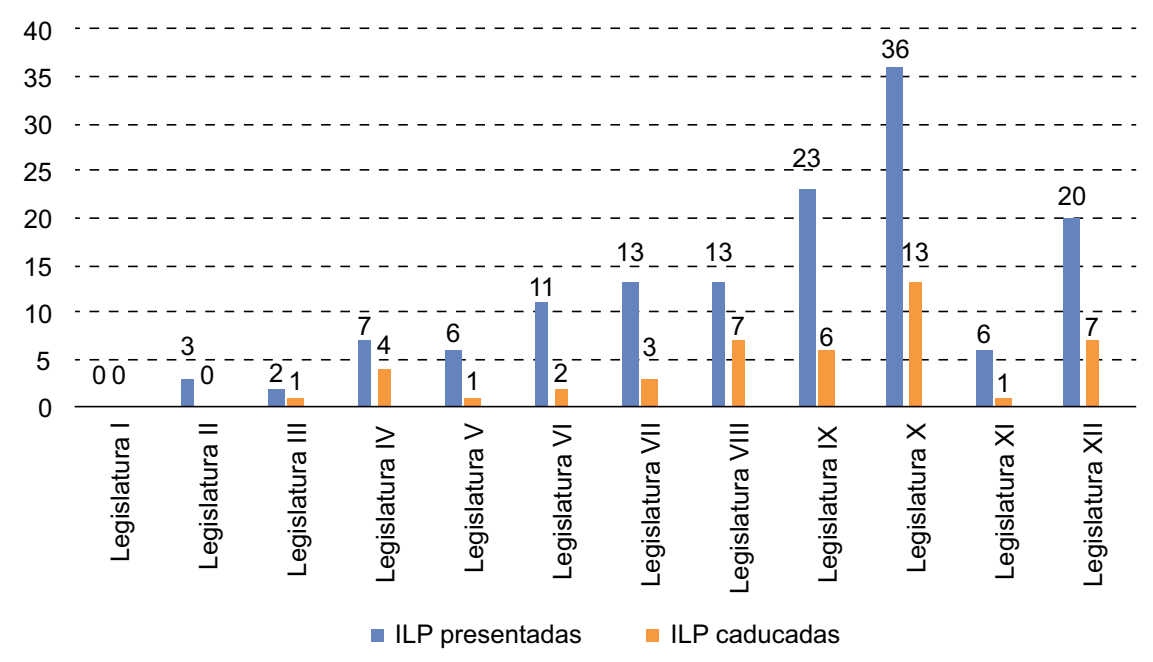

${ }^{34}$ En este sentido se expresan, entre otros, Rubio Llorente (1993: 261) o Presno Linera (2012: 100).

35 Elaboración propia a partir de los datos extraídos del Portal Web de la Junta Electoral Central: http://www.juntaelectoralcentral.es/cs/jec/ilp/legislaturas 
Esto nos lleva al segundo de los elementos que pretende modificar la proposición. La actual regulación constitucional habla de que para la presentación popular de proposiciones de ley «se exigirán no menos de 500.000 firmas acreditadas». El texto de la propuesta asturiana dice, por su parte, que «se exigirán 500.000 firmas acreditadas». El cambio, pues, es evidente. En la regulación actual el medio millón de firmas es un mínimo constitucional, pudiendo el legislador orgánico fijar cualquier cifra superior -la Ley Orgánica 3/1984 ha decidido, no obstante, mantener la cifra. Con la modificación propuesta por la Junta General del Principado, el Parlamento no podría en ningún caso incrementar el umbral de firmas exigido.

La propuesta es positiva, pero a todas luces insuficiente. Existe gran consenso en la doctrina ${ }^{36}$ en torno a la calificación de las quinientas mil firmas como una cifra desproporcionada. De hecho, en el derecho comparado encontramos no pocos ejemplos de países con cifras mucho más bajas. Ténganse en cuenta, por ejemplo, las 200.000 firmas previstas en Austria, las 100.000 exigidas en Polonia o Rumania, las 50.000 fijadas en Italia, o las 35.000 que exige Portugal. Por dar un dato más impactante, la iniciativa legislativa popular en la Unión Europea (28 países con más de 500 millones de habitantes) requiere tan solo un millón de firmas. En consecuencia, la modificación planteada resulta sumamente tímida, siendo conveniente acometer una reducción en el umbral de firmas exigido.

Al elevado número de firmas hay que unir un plazo para su recolección relativamente breve: seis meses, que fueron ampliados a nueve en $2006^{37}$. Atendiendo a la elevada tasa de proposiciones caducadas, parece clara la necesidad de incrementar el plazo disponible para la tarea. Especialmente si no hay modificación a la baja del número de firmas requerido.

Así pues, el cambio proyectado presenta luces y sombras. Dar la posibilidad de que los ciudadanos lancen sus propias propuestas en materias de relevancia como aquellas propias de ley orgánica puede incrementar el interés por la figura, revitalizando así el contacto entre representantes y representados. El número de firmas, sin embargo, sigue siendo muy elevado, especialmente si recordamos que estamos ante una mera propuesta a las Cortes para que arranquen el procedimiento legislativo, sin ningún tipo de vinculación al respecto. Tendría sentido mantener un número tan elevado de firmas si la iniciativa, como ocurre en Suiza y en algunos estados de los Estados Unidos, quedara vinculada al referéndum. En ambos modelos, en

${ }^{36}$ Véanse, entre otros, Biglino Campos (1987: 100), Aguiar de Luque (2000: 92) o Díaz-Revorio (2018: 254).

37 Artículo 7.3 de la Ley Orgánica 3/1984, modificado por la Ley Orgánica 4/2006. El precepto establece la posibilidad de que la Mesa del Congreso otorgue una prórroga de tres meses, «cuando concurra una causa mayor». 
efecto, los ciudadanos pueden plantear una modificación legal al Parlamento, produciéndose una llamada a referéndum si éste decide rechazar la propuesta. En Suiza, además, el Parlamento tiene la facultad de presentar una contrapropuesta, que será votada por los electores de manera conjunta con la proposición ciudadana. En estos supuestos sería lógico que el número de firmas exigido para plantear la iniciativa no fuera escueto, pues la propuesta puede terminar por desencadenar una consulta popular. En modelos como el nuestro, donde la negativa del Parlamento no tiene consecuencia alguna, plantear un umbral de firmas tan elevado carece de toda lógica. Se echa en falta, pues, mayor atrevimiento por la Junta General del Principado a este respecto.

\section{LOS CAMBIOS PROPUESTOS (II): LA REFORMA DEL ARTÍCULO $92 \mathrm{CE}$}

El planteamiento más ambicioso de la propuesta asturiana se centra en el artículo 92 de la Constitución. La disposición, heredera de aquel rico artículo 85 originalmente diseñado por la ponencia constituyente, contempla en la actualidad una única modalidad de referéndum: el estatal de carácter consultivo a iniciativa exclusiva del Presidente del Gobierno para decisiones políticas de gran trascendencia. No parece necesario dedicar demasiado espacio en recordar la escasa virtualidad práctica que este referéndum ha tenido en las cuatro décadas acontecidas desde que la Constitución fue aprobada. Se han celebrado tan solo dos consultas, una relativa a la permanencia de España en la Organización del Tratado del Atlántico Norte (1986), y otra sobre el Tratado Constitucional Europeo (2005).

Ante el escaso recorrido de la figura, la proposición de reforma constitucional aquí estudiada trata de revitalizar el empleo del referéndum en el ámbito estatal a través de dos medidas principales: i) incorporar a la ciudadanía como sujeto titular de iniciativa para poner en marcha un referéndum consultivo; y ii) la recuperación del referéndum derogatorio originalmente previsto en el artículo 85 del Anteproyecto constitucional. Al estudio separado de ambas propuestas dedicados los siguientes apartados.

\section{La incorporación de la iniciativa popular al referéndum consultivo}

El primer párrafo del proyectado artículo 92 establece, en efecto, que la consulta sobre decisiones políticas de gran trascendencia será convocada «por el Rey, a propuesta del Presidente del Gobierno, previamente autorizado por el Congreso de los Diputados, o a iniciativa de quinientos mil electores». Se pretende romper, así, el monopolio que la mayoría política del momento ostenta para convocar este tipo de referendos. La propuesta ha sido 
ampliamente defendida por la doctrina, que considera que contribuye a eludir intentos de legitimación personal a través de consultas populares ${ }^{38}$.

Recuérdense, en este sentido, las palabras de Lijphart: «cuando los gobiernos controlan el referéndum tienden a usarlo solo cuando esperan ganar» (1984: 204). Constituye un buen ejemplo al respecto la experiencia francesa en los primeros tiempos de la V República, con el Presidente De Gaulle empleando el referéndum como instrumento de legitimación personal ${ }^{39}$. Así pues, ampliar el abanico de sujetos legitimados para poner en marcha la convocatoria de un referéndum puede ayudar a reducir las posibilidades de empleo torticero del mismo. Nótese que evitamos emplear el término «eliminar», pues creemos que nada garantiza que un referéndum que sea convocado a instancias de la ciudadanía no termine por ser convertido por los partidos en un plebiscito sobre el gobierno o su líder. LeDuc (2015: 140) es de esta opinión, y pone el ejemplo de la oleada de iniciativas populares sobre el matrimonio homosexual y el aborto que, respaldada por el Partido Republicano, aconteció en los meses previos a las elecciones presidenciales de 2004, y que pretendía movilizar al electorado conservador como vía de legitimación de las políticas de la Administración Bush.

La propuesta original que fue planteada en la Junta General del Principado de Asturias por el grupo de Izquierda Unida contemplaba la posibilidad de poner en marcha este referéndum, además de por quinientos mil ciudadanos, por las Asambleas de tres Comunidades Autónomas. Esta posibilidad fue, finalmente, excluida del texto definitivo. Consideramos, sin embargo, que la medida hubiera sido positiva, pues, como dice Requejo Rodríguez (2014: 280), ello permitiría implicar a las diversas partes que componen la organización territorial del Estado «en decisiones que afectan al todo» ${ }^{40}$. Al requerir que la propuesta venga avalada por una pluralidad de Comunidades (tres en la propuesta original), se garantiza, además, que el móvil de su actuación sea el interés general y no intereses particulares. Sea como fuere, la ruptura del monopolio gubernamental en la iniciativa del referéndum consultivo debe verse con buenos ojos.

\section{La incorporación del referéndum abrogativo}

La medida de mayor calado de todas cuantas recoge la propuesta asturiana consiste en la incorporación del referéndum al ámbito legislativo. Recuérdese

${ }^{38}$ Véanse, entre otros, Castellà Andreu (2016: 261), Requejo Rodríguez (2014: 276), Garrido López (2017: 217).

39 Un detallado análisis sobre la cuestión se encuentra en Pérez Sola (1992: 336-343).

${ }^{40}$ Mismo criterio mantiene Castellà Andreu (2016: 261), que entiende que la incorporación de los parlamentos autonómicos entre los sujetos legitimados para plantear la convocatoria de un referéndum serviría para «favorecer la integración territorial en las decisiones fundamentales del Estado». 
que el artículo 85 del Anteproyecto constitucional preveía la posibilidad de someter a referéndum i) leyes aprobadas en el Parlamento y aún no sancionadas, y ii) la derogación de leyes plenamente en vigor. El radical recorte emprendido sobre esta propuesta original dejó prácticamente vacío de contenido el precepto, perviviendo tan solo el referéndum consultivo sobre decisiones políticas de gran trascendencia. Según ha reconocido unánimemente la doctrina, este referéndum no puede emplearse en el terreno legislativo, de modo que a su través los ciudadanos no pueden pronunciarse sobre textos legales ${ }^{41}$. En consecuencia, el cuerpo electoral no dispone de capacidad alguna de control sobre la producción legislativa de las Cortes Generales.

La proposición de reforma constitucional pretende, pues, recuperar parcialmente la propuesta original de la ponencia, dando la posibilidad de que los ciudadanos deroguen en referéndum normas aprobadas por el Parlamento. Nótese que esto resolvería un notable error técnico en la ubicación del actual artículo 92, que pervive en el capítulo II del Título III, «De la elaboración de las leyes», simplemente por la inercia de su redacción primigenia, pues no tiene ya influencia alguna sobre la producción legislativa. Con su contenido actual, el precepto encajaría mejor en el Título IV, del Gobierno y de la Administración, o tal vez en el V, sobre las relaciones entre el Gobierno y las Cortes Generales, al requerir el primero autorización de las segundas para lograr la convocatoria de la consulta.

La propuesta supone, igualmente, retomar de algún modo un precedente en la historia constitucional española, pues el texto republicano de 1931, siguiendo la estela de la Constitución de Weimar, recogía un referéndum legislativo. Su artículo 66 establecía, en efecto, la posibilidad de que el pueblo atrajera «a su decisión mediante referéndum las leyes votadas por las Cortes». Para ello bastaba con que lo solicitara el 15\% del cuerpo electoral. No era posible, añadía el precepto, emplear este recurso sobre el texto de la Constitución, las leyes complementarias de la misma, las de ratificación de Convenios internacionales inscritos en la Sociedad de las Naciones, los Estatutos regionales, ni las leyes tributarias. La Constitución no especificaba si el texto sobre el que una porción del electorado podría forzar una votación habría o no de estar en vigor. Es decir, no quedaba claro si se estaba ante un referéndum suspensivo frente a leyes aprobadas y aún no sancionadas, o ante un referéndum derogatorio de normas legales en vigor. El hecho de que la figura fuera incluida en la Constitución a raíz de un voto particular planteado por el diputado Castrillo en la Comisión de

41 Véanse, por todos, Oliver Araujo (1989: 158), Linde Paniagua y Herrero Lera (1979: 40) o Rodríguez Zapatero (1986: 1162). En todo caso, como con acierto apunta Requejo Rodríguez (2014: 264), nada impide que, una vez celebrado el referéndum, se termine por plasmar su resultado en una ley. 
Constitución, que pretendía incluir un referéndum de tipo suspensivo ${ }^{42}$, parece respaldar la teoría de que la consulta del artículo 66 iría en la misma línea ${ }^{43}$. Sea como fuere, el artículo imponía que una ley especial regulara las cuestiones procedimentales del referéndum, así como su iniciativa popular, pero ésta nunca llegó a aprobarse ${ }^{44}$, por lo que nada podemos decir sobre su experiencia práctica.

$\mathrm{Al}$ margen de estos antecedentes propios, parece claro que si se habla de referéndum abrogativo la mirada debe volverse hacia la experiencia italiana. El artículo 75 de la Constitución de 1947 permite que medio millón de electores soliciten la convocatoria de un referéndum sobre la derogación total o parcial de una ley. Como dijo Bettinelli (1975: 311), la existencia de este referéndum supone la sustracción «al Parlamento de la exclusividad de la función legislativa». Mortati (1976: 836) llegó a afirmar, de hecho, que el régimen democrático creado por la Constitución podía calificarse de tipo «mixto», pues los ciudadanos adquieren la capacidad no solo de designar representantes, sino también de fijar posiciones sobre asuntos concretos, «poniéndose en una posición de alejamiento o incluso de contraposición respecto a la voluntad hecha valer por el Estado». En efecto, la figura deja un margen de maniobra relativamente amplio a los ciudadanos, lo que ha sido efectivamente aprovechado por éstos, convirtiendo a Italia en uno de los países europeos con más consultas populares celebradas a nivel nacional: desde $1970^{45}$ se han

${ }^{42}$ Véase el Diario de Sesiones de las Cortes Constituyentes, Apéndice $10^{\circ}$ al núm. 26, de 25 de agosto de 1931, p. 6. En él el diputado Castrillo sugería la posibilidad de someter las normas aprobadas por las Cortes a referéndum de ratificación por el pueblo, exigiéndose para ello: i) solicitud dentro del plazo de quince días fijado para someter las leyes a la promulgación; y ii) que lo pidiera el Gobierno, la tercera parte de los parlamentarios o un número de electores que no bajara del millón.

43 Son de esta opinión Presno Linera (2017: 59) y Cuesta López (2008: 75).

44 Pérez Sola (1994: 17) subraya la gran desconfianza que la herramienta suscitaba en la Cámara, recurriendo a una frase de Alcalá Zamora sobre la ley especial que había de desarrollar su regulación: «Los de centroderecha eludieron presentarla; los de izquierda, tendencia que ya en las constituyentes quiso cerrar el paso al artículo 66 e impusieron casi todas las restricciones que éste contiene, se negaron rotundamente».

45 Pese a que la Constitución data de 1948, el instituto referendario no arrancó su andadura efectiva hasta 1970, pues la aprobación de la ley que debía desarrollar su regulación fue sistemáticamente demorada. El bloqueo llegó a su fin a raíz de la presentación en el Parlamento de una propuesta de legalización del divorcio, que dividió a la coalición gobernante de centroderecha. Ante la presión de sus socios liberales, la Democracia Cristiana aceptó no impedir la aprobación parlamentaria de la ley, a cambio de que fuera previamente adoptada la normativa reguladora del referéndum, con vistas a activar una primera consulta contra aquella. Así, el 25 de mayo de 1970 fue aprobada la ley no 352 , de normas sobre los referendos previstos en la Constitución y sobre la iniciativa legislativa del pueblo, lográndose la adopción de la ley del divorcio el 1 de diciembre del mismo año. 
celebrado nada menos que 71 referendos, de los cuales 67 han sido abrogativos $^{46}$.

Bajo estas influencias, la proposición crea un referéndum derogatorio de cuyos elementos principales pasamos a ocuparnos.

\subsection{Iniciativa}

La propuesta original registrada por Izquierda Unida en la Junta General del Principado recogía la posibilidad de activar la convocatoria del referéndum consultivo a propuesta del Gobierno, a iniciativa de cualquiera de las Cámaras, de tres Asambleas de Comunidades Autónomas o de quinientos mil electores. Como puede comprobarse, el abanico de sujetos legitimados era idéntico al que preveía el Anteproyecto constitucional, con la única salvedad de que éste fijaba el umbral de firmas para la iniciativa popular en setecientas cincuenta mil. Como ya se ha reiterado, fruto de la tramitación parlamentaria la iniciativa quedó reducida únicamente a los ciudadanos. Se sigue, pues, la misma lógica del texto republicano de 1931 en relación con el referéndum suspensivo.

Encontramos positivo que sean los ciudadanos los que, reuniendo el medio millón necesario de firmas, puedan someter a control del entero cuerpo electoral las normas aprobadas por las Cortes. La práctica demuestra que, cuando la iniciativa se deja en manos de las autoridades, el referéndum adquiere un grado de influencia menor. Sirva como ejemplo el caso irlandés, donde la iniciativa es dejada en manos de las Cámaras ${ }^{47}$, y ello ha motivado su nulo empleo en la práctica. En Dinamarca la iniciativa corresponde a un tercio de los parlamentarios ${ }^{48}$, y desde 1963 tan solo se han convocado cuatro consultas. Muy diferente es la experiencia italiana, donde, como ya se ha dicho, la herramienta puesta en manos de los ciudadanos ha sido empleada de manera profusa. Sáenz Royo (2016: 133) destaca cómo la iniciativa popular ha permitido «introducir en el debate público temas al margen de la voluntad de los grandes partidos», operando como útil contrapeso institucional.

El número de firmas previsto, quinientas mil, es relativamente elevado, sobre todo si tenemos en cuenta que España tiene un censo electoral casi 14 millones más pequeño que el italiano. Ello supone que la consecución del objetivo quede en manos de organizaciones relativamente potentes a nivel personal y económico, como los partidos políticos. De este modo, el intento

${ }^{46}$ Datos extraídos del Archivio Storico delle elezioni-Dipartimento per gli Affari Interni e Territoriali, Ministero dell'Interno, accesible desde: http://elezionistorico.interno. gov.it/ (consultado el 14 de marzo de 2019).

47 Artículo 27 de la Constitución irlandesa de 1937.

48 Artículo 42 de la Constitución danesa de 1953. 
de otorgar a los ciudadanos un instrumento que les permita actuar de manera autónoma quedaría algo diluido. En Italia, donde, como decimos, las quinientas mil firmas suponen un porcentaje algo más asequible en relación con el entero cuerpo electoral, este problema ha sido frecuentemente señalado ${ }^{49}$. De hecho, el Partido Radical empleó la figura de manera recurrente como vía para publicitar su propio programa político ${ }^{50}$. No resulta sencillo, en todo caso, lograr un equilibrio en el número de firmas requerido para evitar, por un lado, que las consultas solo puedan ser activadas por grupos sociales poderosos y, por otro, que sean convocadas en número excesivo.

A diferencia de lo previsto en la propuesta original de Izquierda Unida, no se contempla la posibilidad de que las Comunidades Autónomas ostenten papel alguno en el proceso de iniciativa. Aquella redacción primigenia, en efecto, permitía que las Asambleas de tres Comunidades Autónomas pudieran activar la convocatoria del referéndum abrogativo. Esta posibilidad está presente en Italia, donde cinco consejos regionales -por decisión adoptada por mayoría absoluta en cada uno- pueden poner en marcha el procedimiento de consulta ${ }^{51}$, o en Suiza, donde ocho cantones pueden someter a referéndum una ley aprobada por el Parlamento federal. Como ya se ha dicho con anterioridad, creemos que esta opción sería útil a los fines de integrar a las diversas partes del Estado en la toma de decisiones global, algo que, a falta de una auténtica cámara de representación territorial en nuestro país, continúa siendo un objetivo pendiente. Por esta vía, aunque de manera limitada, las Comunidades podrían tener un papel de mayor importancia. Ello permitiría generar un incentivo positivo en las Cortes Generales para tener más presentes los intereses autonómicos a la hora de adoptar decisiones.

\subsection{Objeto}

La proposición habla de la posibilidad de someter a referéndum derogatorio «la derogación de leyes en vigor». Pese a la aparente claridad del texto, pueden plantearse no pocos elementos de reflexión en torno a la cuestión de cuál puede ser el objeto efectivo de la consulta. Así:

1) El artículo proyectado habla de leyes en vigor, sin especificar si la derogación pretendida debe referirse al texto legal en su globalidad o

49 Véase, por ejemplo, Olivetti (2007: 153).

${ }^{50}$ Destaca en este sentido la batería de referendos auspiciados por el partido en 1997, que incluía temáticas como la carrera de los magistrados, el servicio militar, la caza, o diversos procesos de privatización de sociedades públicas.

${ }^{51}$ La práctica, sin embargo, acredita un empleo escasísimo de la iniciativa regional. Tan solo un referéndum abrogativo, el convocado en 2016 sobre las concesiones para la extracción de hidrocarburos, se ha realizado a iniciativa de cinco consejos regionales. 
si, por el contrario, es posible acotarla a disposiciones concretas. La Constitución italiana establece, en este sentido, que el referéndum abrogativo puede emplearse para decidir sobre «la derogación total o parcial de una ley». Convendría, pues, afinar la literalidad del precepto y aclarar si el referéndum puede referirse únicamente a una parte (un artículo, un capítulo, un título...) del texto legislativo.

2) En el supuesto de que sea aceptado el referéndum para la derogación parcial de leyes, ello puede generar consecuencias de no poca relevancia. En efecto, esta posibilidad ha sido empleada en Italia para, a través del recorte selectivo de partes de una determinada normativa, pretender obtener una disciplina distinta de la previamente existente. Y ello en tanto resulta evidente que a través de la supresión de unas pocas palabras de un texto su significado regulatorio puede variar diametralmente. A este tipo de referendos se les ha denominado «manipulativos» ${ }^{52}$. El debate que abran las Cortes Generales sobre la conveniencia de instaurar el referéndum abrogativo debería tener presente la posibilidad de que éste experimente este tipo de mutación hacia algo parecido a un referéndum propositivo.

3) La propuesta contempla una serie de materias en las que, por su importancia, no está permitido el empleo del referéndum: tributarias, presupuestarias o de carácter internacional, así como lo relativo a la prerrogativa de gracia. El listado es plenamente coincidente con el previsto en el artículo 75 de la Constitución italiana, por lo que su influencia es indiscutible. Además de estas exclusiones expresas, parece evidente que el referéndum tampoco podría utilizarse sobre i) artículos constitucionales; ii) leyes aprobadas y aún no en vigor; iii) leyes autonómicas; y iv) disposiciones reglamentarias.

Existen, por otro lado, otras materias no previstas en el elenco ofrecido por la propuesta en las que un referéndum podría generar no pocos inconvenientes. Pensemos, por ejemplo, en las leyes electorales. Parece claro que permitir su supresión simple y directa podría generar una crisis institucional de gravedad, pues hasta que el

${ }^{52}$ El criterio de la Corte Constitucional italiana sobre este tipo de operaciones ha variado a lo largo de los años, pudiendo apreciarse hasta tres fases diferentes. Así, en un primer momento permitió, e incluso fomentó, su empleo en materia electoral (véanse las sentencias 29/1987 o 47/1991). En una segunda fase la Corte decidió cortar en seco esta práctica, prohibiéndola aunque el resultado del recorte fuera la generación de una normativa solo parcialmente novedosa (véase la sentencia 36/1997). En la tercera fase, la Corte dio algo de margen a las tácticas manipulativas, situando el listón para su prohibición en la creación de una disciplina completamente diferente a la original (destacan al respecto las sentencias 43/2003 o 28/2011). Para un análisis detallado de esta evolución puede consultarse Malfatti, Romboli y Panizza (2017: 280-282). 
Parlamento elaborara una nueva normativa el país carecería de las reglas necesarias para renovar sus cargos democráticos ${ }^{53}$. Todo ello, claro está, salvo que se decidiera que la derogación de la ley electoral vigente supone la recuperación de la normativa sustituida por ésta en su día, cuestión sobre la que se ha reflexionado en Italia ${ }^{54}$. Ofrecemos este ejemplo para ilustrar la necesidad de un debate parlamentario de fondo que, en caso de aprobar la propuesta asturiana, resuelva este tipo de incógnitas.

4) Nada dice la propuesta sobre algunas consecuencias cruciales de la aprobación/rechazo del referéndum en relación con la normativa finalmente resultante. Así, en primer lugar, surge la duda de si el Parlamento, una vez derogada una ley a través del referéndum, puede volver a aprobar una norma de idéntico contenido. En Italia esta cuestión ha sido problemática. Por un lado, la mayoría de la doctrina y la Corte Constitucional entienden que referéndum y legislación ordinaria se encuentran al mismo nivel, sin que pueda hablarse de un «plusvalor» en las decisiones populares. Sin embargo, y de manera difícilmente compatible con lo anterior, la propia Corte ha establecido la prohibición de que las Cámaras reintroduzcan la ley derogada mientras no se verifiquen cambios del «marco político» o las «circunstancias de hecho» (sentencia 199/2012) ${ }^{55}$. Sin poder entrar aquí en el

${ }^{53}$ Encontramos un ejemplo al respecto en Italia, donde la Corte Constitucional rechazó en sentencia n. 13 de 2012 la admisión de un referéndum solicitado por más de un millón de ciudadanos frente a una reforma de la ley electoral (la conocida como ley Calderoli), argumentando la necesidad de evitar vacíos legislativos que, en caso de triunfo de la consulta, podrían producirse en una normativa imprescindible para la celebración de unas próximas elecciones generales y, por consiguiente, para el entero régimen democrático.

${ }^{54} \mathrm{La}$ Corte Constitucional ha sostenido siempre que la abrogación a través de referéndum nunca puede determinar la reviviscencia de la ley originalmente derogada (sentencias 31/2000, 24/2011 o 13/2012). El argumento central para defender esta regla radica en la expresa configuración constitucional dada al referéndum. Éste, en efecto, es exclusivamente abrogativo, no decisivo. Por ello, a través del referéndum no es posible hacer lo mismo que el Parlamento, que tiene capacidad para limitarse a abrogar, para introducir nuevas reglas sin abrogar otras, o para introducir nuevas reglas abrogando las precedentes. Algunos autores, entre los que puede citarse a Rescigno (2011: 756), defienden el empleo de la reviviscencia en casos excepcionales, en los que la abrogación genere una laguna jurídica insalvable, y como medio para evitar tener que optar por inadmitir un referéndum, opción siempre lesiva para el principio de soberanía popular. Interesantes reflexiones en la materia pueden también encontrarse en Luciani (2006) o Nocilla (2011).

${ }^{55}$ Ferri (2015: 230-231) enfatiza que la Corte Constitucional ya había reconocido en las sentencias 468/1990 y 32/1993 esta prohibición de reproducción de la ley derogada, aunque sin llegar a establecer pautas claras sobre su duración. De este modo, la sentencia 199/2012 es la primera que especifica el límite en cuestión, declarando que será efectivo 
fondo de la cuestión, nos parece conveniente que un punto tan sensible quede despejado en la tramitación parlamentaria de la proposición de reforma constitucional.

En segundo lugar, ¿qué consecuencias tiene el rechazo de la propuesta abrogativa sometida a referéndum? ¿Puede volver a activarse el procedimiento referendario sin límite temporal? En Italia la cuestión ha sido resuelta por la ley 352/1970, reguladora del referéndum, disponiendo que en un plazo de 5 años no podrá volver a solicitarse la derogación de la misma norma (artículo 38). Aunque puede haber debate en torno al plazo concreto que deba fijarse -tal vez con 3 años sea suficiente-, no resulta cuestionable la necesidad de una medida de este tipo, pues permite evitar que la vigencia de una misma norma se encuentre continuamente cuestionada. Nótese que esta restricción no opera cuando el referéndum naufraga por no haberse alcanzado el quórum de participación, pues en rigor no estamos ante una votación «negativa» sino «nula». Es decir, técnicamente el pueblo no habría llegado a manifestar su rechazo a la derogación.

5) Precisamente el último de los elementos a considerar es el del quórum de participación. La proposición de reforma establece, de manera idéntica al artículo 75 de la Constitución italiana, que «el resultado del referéndum será vinculante cuando haya participado en la votación la mayoría de quienes tengan derecho a hacerlo». Este es, probablemente, el aspecto menos satisfactorio de la propuesta asturiana. Y ello dados los relevantes inconvenientes que esta exigencia conlleva. En efecto, el Código de Buenas Prácticas sobre referendos elaborado en 2007 por la Comisión de Venecia (Consejo de Europa) recomienda eliminar este quórum (punto 7), pues «asemeja a los votantes que se abstienen a aquellos que votan en contra de la propuesta». El memorándum explicativo del Código ofrece un ejemplo a este respecto. Supongamos que hay un $48 \%$ de electores a favor de la propuesta sometida a referéndum, un $5 \%$ en contra y un $47 \%$ de abstención. El electorado opositor tendrá el incentivo de no participar en la votación para lograr su fracaso, pudiendo lograr su objetivo pese a ser una clara minoría.

Ocurre, de hecho, que en Italia se ha verificado la existencia de este tipo de estrategias ${ }^{56}$. Precisamente por ello, la reforma constitucional impulsada por Matteo Renzi en 2016 planteaba la reforma del artículo 75, disponiendo

\footnotetext{
hasta que se produzcan cambios en el marco político (parece razonable entender por tal la renovación de las Cámaras en elecciones) o en las circunstancias de hecho.

${ }^{56}$ De los 67 referendos abrogativos celebrados desde 1970, 28 han naufragado por no alcanzarse el quórum exigido.
} 
que para aquellas propuestas que alcanzaran las 800.000 firmas el quórum de participación ya no sería el de la mayoría del cuerpo electoral, sino el de la mayoría de los electores que hubieran participado en las últimas elecciones a la Cámara de Diputados. Lo positivo de esta propuesta es, fundamentalmente, que toma conciencia de la existencia de un problema y trata de corregirlo. El problema es que la solución propuesta es claramente insuficiente. Como han escrito Romboli y Panizza (2016: 37), si se ha asumido que la actual exigencia de quórum está motivando tácticas torticeras por parte de los opositores a las medidas sometidas a referéndum, no se entiende por qué la reforma se plantea en términos de «premio» para determinadas propuestas en lugar de como solución general. Y ello en tanto en cuanto el referéndum derogatorio «es claramente para el uso de la minoría, y el alcance de un número más alto de firmas es ciertamente más fácil para una minoría organizada que para aquella no vinculada a partidos o sindicatos, para la cual la abrogación de una ley por vía referendaria se haría más dificultosa».

Así pues, sería recomendable que el sistema de quórum diseñado por la propuesta de reforma fuera corregido en su tramitación parlamentaria. La modificación debería pasar o bien por su pura y simple supresión, como aconseja la Comisión de Venecia, o bien por su relajación, fijando su cálculo a partir del dato de participación en las anteriores elecciones generales.

En conclusión, pese a que la incorporación de este instituto debe verse con buenos ojos, pues otorga a los ciudadanos una intensa capacidad de control sobre la acción de sus representantes, son muchos los interrogantes que deberían recibir una respuesta clara a lo largo del procedimiento parlamentario. De lo contrario, habrá de ser la jurisprudencia constitucional quien - como ha ocurrido en Italia- venga a tratar de cubrir las múltiples lagunas existentes al hilo de su ejercicio práctico. Y ello no siempre es sencillo, pues el control de constitucionalidad en materia de decisiones directas de los ciudadanos se torna complejo y de consecuencias no siempre previsibles.

\section{LOS CAMBIOS SUGERIDOS (III): LA REFORMA DEL ARTÍCULO $166 \mathrm{CE}$}

La última de las modificaciones constitucionales propuesta por la proposición de la Junta asturiana consiste en extender el ámbito de la iniciativa de reforma constitucional, para incluir en ella a los ciudadanos. De esta manera, se propone que el artículo 166 se remita en la identificación de los sujetos legitimados para poner en marcha el proceso de reforma constitucional al conjunto de los apartados del artículo 87 , sin excluir el tercero.

Lo que se propone, pues, es recuperar una medida que ya estaba presente en el Anteproyecto de Constitución elaborado por los siete ponentes, y que fue suprimida después en la Comisión de Asuntos Constitucionales y 
Libertades Públicas. Tal vez sea útil, a nuestros efectos, recordar brevemente los términos en que se produjo el debate sobre esta supresión. Como dijimos, fue el diputado Cisneros el que sugirió la misma ${ }^{57}$, y lo hizo entendiendo que la iniciativa popular «desnaturalizaría» la configuración del proceso de reforma constitucional que se estaba forjando. Una configuración fundamentalmente «rígida», con mayorías cualificadas y apelación al referéndum, por lo que, en su opinión, incorporar la iniciativa popular supondría ir en contra de esta regulación.

El diputado Fraga Iribarne, como ya hizo en relación al artículo 85 original, tomó la palabra para defender la pervivencia de la iniciativa popular ${ }^{58}$. En su criterio el procedimiento de reforma constitucional debería guardar cierto equilibrio, «y ese equilibrio se encuentra en todas las partes del proceso de reforma, lo mismo en la iniciativa (...) que luego en quien resuelve». A ello añadió su temor a que la figura suprimida sirviera para «reforzar la partitocracia», y criticó que se estuviera dando una nueva vuelta de tuerca «al frustrante proceso que estamos siguiendo desde hace unas semanas de restringir todo lo que podemos las iniciativas populares directas»».

Para defender el sentido de la enmienda unieron sus voces los diputados Peces-Barba y Solé Tura. El primero, en una intervención durísima ${ }^{59}$, afirmó que «esa iniciativa no es ni tiende a favorecer la existencia de la democracia, sino, por el contrario, a causar graves dificultades a la democracia». Además, dijo, estas iniciativas «recuerdan mucho más a las fórmulas plebiscitarias o incluso a esas agrupaciones de ciudadanos que se producían para aclamar a los líderes de los regímenes autoritarios en la época del General Perón o del General Franco». Teniendo en cuenta que estamos ante una mera iniciativa, cuyo destino queda totalmente en manos del criterio de las Cortes Generales, la afirmación resulta exagerada. El diputado Fraga Iribarne respondió con ironía $^{60}$, afirmando que pensaba escribir una carta a Suiza, de la que acababa de regresar, «contando esa historia peronista del señor Peces-Barba, que va a ser el éxito cómico del año».

Solé Tura, por su parte, optó por continuar la estrategia argumental emprendida en la defensa de su enmienda al primigenio artículo 85. Esto es, señalar la necesidad de «consolidar un sistema de partidos que hoy es tremendamente precario ${ }^{61}$. Esta apuesta por asentar el funcionamiento del Parlamento como núcleo del Estado y de los partidos como canales de expresión,

57 Véase el Diario de Sesiones del Congreso de los Diputados - Comisión de Asuntos Constitucionales y Libertades Públicas, núm. 83, de 20 de junio de 1978, p. 3463.

58 Ibid., p. 3464.

59 Ibid., p. 3465.

60 Ibid.

${ }^{61}$ Ibid., p. 3466. 
fue respaldada por la mayoría de grupos, quedando la enmienda propuesta por Cisneros aprobada por 27 votos a favor, uno en contra y una abstención.

Es posible que el objetivo destacado por Solé Tura fuera, en efecto, prioritario. Tras cuatro décadas de negación absoluta de pluralismo político y democracia, España trataba de construir un edificio constitucional cuyos cimientos debían anclarse en sólidas bases. Así pues, como sostiene Pérez Royo (1987: 149), puede que en aquel momento incorporar al pueblo al elenco de sujetos capaces de activar la reforma constitucional hubiera supuesto «abrir la puerta a un elemento de confusión, haciendo generar la ilusión de que hay respuestas simples a problemas complejos, que en nada hubiera servido para hacer arraigar en España la democracia parlamentaria, sino más bien para todo lo contrario».

Sea como fuere, parece claro que, desde un punto de vista teórico, en palabras del maestro De Vega (2011: 134), «resulta difícil asimilar que, en un ordenamiento constitucional como el nuestro, donde se proclama la soberanía popular y el poder constituyente del pueblo, y donde en virtud de esos principios se consagra la iniciativa popular para las leyes ordinarias (art. 87), se la elimine luego para la actuación del poder constituyente» ${ }^{62}$. Por ello, lo que tal vez pudo estar justificado en un contexto muy concreto como fue el de la transición, podría no estarlo hoy.

No son pocas las voces, en efecto, que defienden la incorporación de la iniciativa popular de reforma constitucional a nuestro texto supremo. En opinión de Sáenz Royo (2016: 131), si la Constitución debe ser considerada la obra del pueblo, «el pueblo ha de poder reaccionar contra la usurpación de esa voluntad por el partido que tenga la mayoría en el Parlamento y, por tanto, ni la iniciativa ni la decisión final sobre su reforma puede ser excluida de la participación directa del pueblo ni, por tanto, depender exclusivamente de sus representantes». Mismo criterio defiende Cebrián Zazurca (2017: 87), para el que una relación óptima entre reforma de la Constitución y principio democrático pasaría por reconocer tanto «la posibilidad de iniciar el procedimiento por iniciativa popular» como el referéndum como paso final del mismo, cuya celebración debería dejarse, al menos, a criterio de los ciudadanos. Para Díaz Revorio (2018: 254), en una época donde cada vez parece más evidente la necesidad de abrir un proceso de reflexión sobre la reforma de nuestra Constitución, «tal vez una iniciativa popular pudiera suponer el punto de partida que no se termina de dar, o el empuje necesario para tomarse en serio esta tarea pendiente, cada vez más perentoria».

${ }^{62}$ En sentido coincidente, Presno Linera (2012: 99) habla de «contradicción notable con el principio de soberanía popular (art. 1.2) y con el propio mandato que se impone a los poderes públicos de facilitar la participación de todos los ciudadanos en la vida política (art. 9.2)». 
En definitiva, la propuesta parece ser acreedora de una calificación positiva. Los ciudadanos deben poseer la capacidad para, al menos, sugerir una propuesta de reforma constitucional a sus representantes. Las Cortes Generales seguirán ostentando la última palabra al respecto, pero no podrán eludir tomar posición sobre reivindicaciones ciudadanas muchas veces olvidadas. La propuesta hubiera sido completa si, además, se hubiera previsto que en el procedimiento de reforma constitucional el referéndum debiera convocarse si así lo solicitan un número determinado de ciudadanos ${ }^{63}$. La regulación actual deja en manos de una décima parte de las Cámaras la solicitud de convocatoria en el procedimiento del artículo 167, lo cual puede generar problemas. A simple vista pudiera parecer que una reforma constitucional que no resulta cuestionada ni siquiera por el 10\% de los miembros de las Cámaras es una reforma sobre la que hay gran consenso. Pero no debiéramos confundir el consenso que una medida pueda alcanzar en sede parlamentaria con el existente a nivel social. Es perfectamente imaginable, en efecto, que el sentir de los ciudadanos en un momento dado no esté totalmente alineado con el de sus representantes ${ }^{64}$, y precisamente por ello herramientas como la iniciativa popular de referéndum cobran sentido.

\section{REFLEXIONES FINALES}

En 1978, el constituyente tomaba la decisión de forjar una democracia eminentemente representativa, relegando los instrumentos de democracia semidirecta a una posición casi residual. Con ello se daba la espalda a la valiente propuesta forjada por los siete ponentes en el Anteproyecto constitucional, que ofrecía a los ciudadanos amplias capacidades de participación política directa.

En aquel momento pudo el temor a la inestabilidad que podría generar un empleo populista de tales instrumentos en el sistema político. Cuatro décadas de dictadura habían dejado a España como un país sin cultura democrática, sin un sistema de partidos capaz de canalizar eficazmente las demandas de la ciudadanía y sin hábito de transacción parlamentaria. En este contexto, como

${ }^{63}$ Es el caso, por ejemplo, de Italia, donde el referéndum constitucional deberá convocarse si así lo solicitan una quinta parte de los miembros de la Cámara, quinientos mil electores o cinco Consejos regionales.

${ }^{64}$ En esta línea, Cebrián Zazurca (2017: 97) insiste en la inconveniencia de «aplicar criterios representativos a una institución de democracia directa, olvidando — cuando se habla de cifras y de porcentajes - la mediación ofrecida por la aplicación de los sistemas electorales para el Congreso y el Senado (también por lo que afecta concretamente a los que han sido durante muchas Legislaturas los sistemas de partidos fruto de esos sistemas electorales)». 
expuso Solé Tura en los debates constituyentes, la prioridad había de ser la de construir un foro parlamentario fuerte y estable, apoyado en el motor de formaciones políticas igualmente robustas. Y, así, la primigenia intención de forjar un sistema donde la democracia semidirecta tuviera un papel decisivo quedó enterrada por la necesidad imperante del momento.

Han pasado, sin embargo, cuarenta años de aquella decisión. Hoy España es una de las veinte «democracias plenas» del mundo ${ }^{65}$. Goza de un sistema de derechos y libertades amplísimo, de un sistema de partidos plenamente asentado, y de unas instituciones que, con sus lógicas deficiencias, respetan el pluralismo político y funcionan de manera razonable. En definitiva, el contexto en relación a 1978 ha cambiado radicalmente. ¿Tiene sentido, pues, mantener el cerrojo a las herramientas de democracia semidirecta en nuestro país?

La Junta General del Principado de Asturias respondió en sentido negativo en 2014. Creyó necesario que, como en muchos de los países de nuestro entorno, los ciudadanos asumieran nuevas responsabilidades en la toma de decisiones públicas, pudiendo actuar con mayor autonomía. Así, la proposición de reforma constitucional elevada a las Cortes Generales amplía el radio de acción de la iniciativa popular, permitiéndola en materias propias de ley orgánica y en la reforma constitucional, habilita a los ciudadanos a instar la convocatoria del referéndum sobre decisiones políticas de gran trascendencia, y les otorga la capacidad de poner en marcha una votación popular sobre la derogación de leyes.

La propuesta, en términos generales, merece una consideración positiva. Preservando el papel central del Parlamento, confiere a los ciudadanos unas imprescindibles capacidades de control sobre su acción. Capacidades hoy prácticamente inexistentes, con la consiguiente merma en la confianza en un sistema político absolutamente dominado por los partidos políticos y sus lógicas internas. La valoración general positiva de la proposición no es óbice para destacar, como hemos hecho a lo largo de este trabajo, algunos elementos que podrían ser objeto de mejora. La rebaja del número de firmas necesario para poner en marcha una iniciativa legislativa popular, la incorporación de la iniciativa autonómica en los dos referendos del artículo 92, y la supresión -o rebaja- del quórum en el referéndum derogatorio se sitúan como los principales.

Por último, debemos destacar que la reforma de los artículos $87.3,92$ y 166 de la Constitución resultaría insuficiente sin una paralela modificación de la Ley Orgánica 2/1980, sobre regulación de las distintas modalidades de referéndum. Y no nos referimos a la obvia adaptación que requeriría la norma

${ }^{65}$ Según el Democracy Index 2018, elaborado por The Economist, y accesible aquí: https://www.eiu.com/public/topical_report.aspx?campaignid=Democracy2018 (consultado el 10 de julio de 2019). 
para alinearse con los cambios constitucionales, sino a la necesidad de corregir defectos serios en el procedimiento común a toda consulta referendaria. De manera muy sintética podemos destacar los siguientes: i) la incorporación expresa a la Ley de la obligación de que toda pregunta sometida al veredicto ciudadano respete el principio de claridad. Esta exigencia, clave para garantizar una expresión libre y consciente del voto, ha sido enfatizada por el Código de Buenas Prácticas sobre referendos de la Comisión de Venecia (punto 3.1 letra c); ii) el reparto de los espacios gratuitos en los medios de difusión de titularidad pública de manera equitativa entre las dos partes en liza en una consulta (como exige el citado Código en su punto 2.2 letra b), en lugar del sistema actual, que realiza la distribución entre los partidos en proporción a sus resultados en las últimas elecciones (artículo 14 LOMR); y iii) la regulación exhaustiva de la financiación de las campañas de referéndum, partiendo de un trato equitativo a los simpatizantes y opositores de la propuesta sometida a votación (punto 2.2 letra a) del Código de Buenas Prácticas).

De poco sirve, en efecto, contar con nuevos instrumentos de participación política directa si su desarrollo normativo no está debidamente afinado. Sin la debida regulación de los elementos citados, el referéndum podría basarse en la manipulación y el engaño, por un lado, y en un injusto desequilibrio de fuerzas entre las partes enfrentadas, por otro. Resulta imprescindible, pues, una adecuada regulación que garantice que la campaña previa a la decisión popular se asienta en una saludable deliberación.

La propuesta asturiana lleva casi cinco años olvidada en el Congreso de los Diputados. Es probable que en nuestro país cualquier reflexión sobre el referéndum como cauce decisorio suponga un cierto tabú por su habitual instrumentalización en el ámbito del secesionismo. Sin embargo, esta espiral debería ser superada. El hecho de que una Comunidad Autónoma insista en la convocatoria de una consulta infraestatal de objeto ilegal no debería coartar el imprescindible debate sobre cómo mejorar los mecanismos de adopción de decisiones en nuestro país. La Junta General del Principado trató de poner en marcha este debate a través de su proposición. Creemos que, al margen de la suerte que deban correr las medidas concretas por ella sugeridas, una democracia consolidada como España debería afrontar una reflexión de estas características cada cierto tiempo. Y cuarenta años son demasiados.

\section{BIBLIOGRAFÍA}

Aguiar de Luque, L. (2000), «Democracia directa e instituciones de democracia directa en el ordenamiento constitucional español». En: Trujillo, G., López Guerra, L., y González-Trevijano, P. (coords.): La experiencia constitucional (19782000), Centro de Estudios Políticos y Constitucionales, Madrid. 
Bettinelli, E. (1975), «Referendum abrogativo e riserva di sovranità», Politica del Diritto, no 3, pp. 305-339.

Biglino CAMPos, P. (1987), «La iniciativa legislativa popular en el ordenamiento jurídico estatal», Revista Española de Derecho Constitucional, nº 19, pp. 75-130.

Castellà Andreu, J. M. (2016), «El referéndum en la Constitución: ¿es necesario un replanteamiento de la institución?». En: Cascajo Castro, J. L. y Martín de la Vega, A.: Participación, representación y democracia - XII Congreso de la Asociación de Constitucionalistas de España, Tirant Lo Blanch, Valencia, pp. 235266.

CEBrián ZAZURCA, E. (2017), Los referéndums de reforma de la Constitución española: un análisis crítico y una propuesta de modificación. En Sáenz Royo, E. y Garrido López, C., La funcionalidad del referéndum en la democracia representativa, Tirant Lo Blanch, Valencia, pp. 77-102.

Cuesta López, V. (2008), Participación directa e iniciativa legislativa del ciudadano en democracia constitucional, Thomson-Civitas, Cizur Menor.

DE VEGA, P. (2011), La reforma constitucional y la problemática del poder constituyente, $7^{\mathrm{a}}$ reimpresión, Tecnos, Madrid.

DíAz-Revorio, F. J. (2018), «Democracia, representación y participación ciudadana, a la búsqueda de un equilibrio que la Constitución no logró», Revista de Derecho Político, no 101, pp. 239-272.

FERRI, G. (2015), «Revocación popular y restricción para el legislador en Italia: la prohibición de restauración se aplica hasta que se produzca un cambio del 'marco político' o 'circunstancias de hecho'», Revista de Derecho Político, n’ 92, pp. 227-244.

García-Escudero Márquez, P. (2006), El procedimiento legislativo ordinario en las Cortes Generales, Centro de Estudios Políticos y Constitucionales, Madrid.

GARcía MAJADO, P. (2017), «La configuración de la iniciativa legislativa popular: resistencias y soluciones», Oñati Socio-Legal Series, vol. 7, no 5, pp. 1041-1057.

GARRIDO LóPEZ, C. (2017), «El debate sobre los riesgos y los límites de los referéndums en perspectiva comparada. En Sáenz Royo, E. y Garrido López, C., La funcionalidad del referéndum en la democracia representativa, Tirant Lo Blanch, Valencia, pp. 185-236.

- (2019), «La iniciativa popular de referéndum», Teoría y Realidad Constitucional, no 43 , pp. 317-345.

Garrorena Morales, Á. (1991), El Estado español como Estado social y democrático de Derecho, Tecnos, Madrid.

Illueca Ballester, J. E. (2018), «La participación política directa en el proceso constituyente español de 1977-78», Historia Constitucional, n 19 , pp. 17-45.

LEDuc, L. (2015), «Referendums and deliberative democracy». Electoral Studies, $38,139-148$.

Lijphart, A. (1984), Democracies: Patterns of Majoritarian and Consensus Government in Twenty-One Countries, Yale University Press, New Haven.

Linde Paniagua, E. y Herrero Lera, M. (1979), «El referéndum en la Constitución española de 1978», Revista de Derecho Político, n 3, pp. 17-48.

Luciani, M. (2006), «Commento all'art. 75». En Pizzorusso, A.: Commentario della Costituzione, Zanichelli, Bologna-Roma, pp. 654 y ss. 
(2008), «El referéndum: cuestiones teóricas y de la experiencia italiana», Revista Catalana de Dret Públic, no 37, pp. 1-15.

Malfatti, E., Romboli, R., y Panizza, S. (2017), Giustizia Costituzionale, 5a Edición, Giappichelli, Torino.

Mortati, C. (1976), Istituzioni di Diritto Pubblico, $9^{a}$ Edición, vol. II, Cedam, Padova.

Nocilla, D. (2011), «Divagazioni sparse su abrogazione, referendum abrogativo e leggi elettorali». En VVAA: Studi in onore di Franco Modugno, vol. III, Editoriale Scientifica, Napolés, pp. 731 y ss.

Olivetti, M. (2007), «Los referendos en serio. La experiencia italiana», Revista Jurídica Universidad Autónoma de Madrid, $\mathrm{n}^{\circ}$ 15, pp. 147-175.

Oliver Araujo, J. (1989), «El referéndum en el sistema constitucional español», Revista de Derecho Político, n 29, pp. 115-182.

PÉrez Sola, N. (1992), «Breve análisis de las experiencias de referéndum en la V República francesa», Revista de Estudios Políticos, n 78, 331-360.

— (1994), La regulación constitucional del referéndum, Universidad de Jaén Secretariado de Publicaciones, Jaén.

Pérez Royo, F. J. (1987), La reforma de la Constitución, Congreso de los Diputados, Madrid.

Presno LinerA, M. Á. (2012), «La participación ciudadana en el procedimiento legislativo como parte de la esencia y valor de la democracia», Asamblea: Revista Parlamentaria de la Asamblea de Madrid, no 27, pp. 87-119.

— (2017), «El referéndum en la Constitución española: límites y posibles reformas». En Sáenz Royo, E. y Garrido López, C., La funcionalidad del referéndum en la democracia representativa, Tirant Lo Blanch, Valencia, pp. 51-75.

RESCIGNO, G. U. (2011), «Reviviscenza di disposizioni giuridiche e referendum abrogativo», Diritto Pubblico, no 3, pp. 713-759.

REQUEJO Rodríguez, P. (2014), «El referéndum consultivo en España: reflexiones críticas y algunas propuestas de futuro», Estudios de Deusto, vol. 62, n ${ }^{\circ} 1, \mathrm{pp}$. 261-284.

Rodríguez ZAPATERo, J. L. (1986), «El referéndum consultivo del artículo 92 en la Constitución española de 1978: un análisis crítico», Diario La Ley, nº 7005, pp. 1156-1186.

Romboli, R. y Panizza, S. (2016), Aspettando il referendum (con el fiato sospeso): Limiti e contenuti della riforma costituzionale Renzi-Boschi, Giappichelli, Torino.

Rubio Llorente, F. (1993), La forma del poder, Centro de Estudios Constitucionales, Madrid.

SÁEnz Royo, E. (2016), «La regulación del referendo en el Derecho Comparado: aportaciones para el debate en España», Revista Española de Derecho Constitucional, $\mathrm{n}^{\mathrm{o}} 108$, pp. 123-153.

Vírgala Foruria, E. (2013), «Crisis de la representación y democracia directa en España», Asamblea: Revista Parlamentaria de la Asamblea de Madrid, n 29, pp. 11-25. 


\title{
RADIOGRAFÍA DE UNA PROPUESTA OLVIDADA: LA PROPOSICIÓN DE REFORMA CONSTITUCIONAL DE LA JUNTA GENERAL ASTURIANA SOBRE DEMOCRACIA SEMIDIRECTA
}

\author{
Overview of a forgotten proposal: The proposal \\ for constitutional reform by the General Council of Asturias \\ on semi-direct democracy
}

\author{
Daniel López Rubio \\ Profesor de Derecho Constitucional \\ Universidad Carlos III de Madrid \\ dlr.eq1@gmail.com / daniel.lopez@uc3m.es
}

http://dx.doi.org/10.18543/ed-67(2)-2019pp263-295

\section{Copyright}

Estudios de Deusto es una revista de acceso abierto, lo que significa que es de libre acceso en su in tegridad. Se permite su lectura, la búsqueda, descarga, distribución y reutilización legal en cualquier tipo de soporte sólo para fines no comerciales, sin la previa autorización del editor o el autor, siempre que la obra original sea debidamente citada y cualquier cambio en el original esté claramente indicado

Estudios de Deusto is an Open Access journal which means that it is free for full access, reading, search, download, distribution, and lawful reuse in any medium only for non-commercial purposes, without prior permission from the Publisher or the author; provided the original work is properly cited and any changes to the original are clearly indicated. 